\title{
The Iranian version of theory-based intention for cesarean section (IR-TBICS) scale: development and first evaluation
}

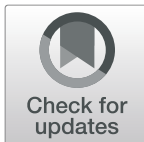

Seyed Abolhassan Naghibi ${ }^{1,2}$, Maryam Khazaee-Pool ${ }^{1,2^{*}}$ (D) and Mahmood Moosazadeh ${ }^{2}$

\begin{abstract}
Background: The rate at which mothers experience a cesarean section in the absence of medical signs is growing worldwide. Women's beliefs and intentions play an essential role in the request or choice of a delivery method. At present, there is no comprehensive, validated scale for assessing pregnant women's beliefs about cesarean section in the Iranian population. This study was performed to develop and assess the validity and reliability of the intention-based cesarean section scale using the theory of reasoned action (TRA) constructs as a theoretical framework for measuring intention toward the selection of a delivery method.
\end{abstract}

Methods: In this cross-sectional validation study, 480 pregnant women were recruited from Sari, in northern Iran, through a multistage random sampling approach. Content validity was examined using the content validity index (CVI) and content validity ratio (CVR). Furthermore, both exploratory factor analyses (EFA) and confirmatory factor analyses (CFA) were applied to assess the construct validity of the developed scale. Reliability was measured by internal consistency and the intraclass correlation coefficient (ICC). Quality criteria for floor and ceiling effects were derived from existing guidelines and consensus within our research group.

Results: The results obtained from the factor analysis showed that the data were fit to the model $(x 2=2298.389$, $P<0.001)$. The TRA comprised 24 items assessing five domains, which described $62.46 \%$ of the common variance. The CFA showed a model with suitable fitness for the data. Cronbach's alpha coefficient for the domains of the scale ranged from 0.609 to 0.843 , and the ICC value ranged from 0.71 to 0.84 , which is within the satisfactory range. The IR-TBICS scale had no floor or ceiling effect on the total score or any of the dimensions.

Conclusions: The belief-based cesarean section scale appears to be a reliable instrument. It is considered suitable and can be applied in other research in Iran.

Keywords: Cesarean section, Intention, Scale development, Psychometrics, Pregnant women

\footnotetext{
* Correspondence: khazaie_m@yahoo.com

'Department of Public Health, School of Health, Mazandaran University of Medical Sciences, Sari, Iran

${ }^{2}$ Health Sciences Research Center, Addiction Research Institutes, Mazandaran

University of Medical Sciences, Sari, Iran
}

(c) The Author(s). 2021 Open Access This article is licensed under a Creative Commons Attribution 4.0 International License, which permits use, sharing, adaptation, distribution and reproduction in any medium or format, as long as you give appropriate credit to the original author(s) and the source, provide a link to the Creative Commons licence, and indicate if changes were made. The images or other third party material in this article are included in the article's Creative Commons licence, unless indicated otherwise in a credit line to the material. If material is not included in the article's Creative Commons licence and your intended use is not permitted by statutory regulation or exceeds the permitted use, you will need to obtain permission directly from the copyright holder. To view a copy of this licence, visit http://creativecommons.org/licenses/by/4.0/ The Creative Commons Public Domain Dedication waiver (http://creativecommons.org/publicdomain/zero/1.0/) applies to the data made available in this article, unless otherwise stated in a credit line to the data. 


\section{Background}

One of the most common significant surgeries around the world is cesarean section, the prevalence of which is increasing worldwide. This increase has caused much concern [1-3]. According to the World Health Organization (WHO), a suitable rate of cesarean section is $10-15 \%$ [4], which is related to the lowest rate of maternal problems. However, based on the results of various studies, the rates of cesarean section are very high in Iran [5-7]. This rate has been reported as 26$60 \%$, although some private clinics have reported up to $87 \%$ [7]. Cesarean delivery on maternal request (CDMR) is responsible for some of the rise in the overall rate. In developed countries, conservative estimates of CDMR range from $4-18 \%$ of all cesarean deliveries [8]. Though the rate of CDMR in Iran remains uncertain due to poor evidence, the CDMR rate is high [9], varying from 11.2$22 \%$ in various studies $[10,11]$.

Many studies have examined the reasons for women's desire for cesarean section. The most common reason in high-income countries is fear of childbirth for various reasons, such as having a traumatic birth experience. $[12,13]$. Reasons for Iranian women to have a cesarean section are mentioned, including a lack of awareness and misrepresentation about natural childbirth [14, 15], the need to plan for the delivery date, fear, and the pain of natural childbirth in a prior delivery experience [16]. Furthermore, a part of this rise is due to the changed attitudes of people toward delivery approaches [17]. Other studies have shown that sociocultural, religious, and economic customs [18, 19], perceived behavioral control, emotional causes, misconceptions, and incorrect subjective norms in Iranian mothers were the main elements in their choice of delivery type [20]. The control of behavior in planning is an important factor to reduce the gap between intention and behavior when encountering various conditions. This high increase in cesarean section indicates a medical problem in Iran and requires the attention of health policy makers to pursue programs to reduce the number of unnecessary cesarean Sect. [21].

It appears that the high rate of cesarean delivery in Iran is a complex phenomenon. Thus, educational interventions to reduce the rate of cesarean delivery, improve the quality of routine vaginal delivery services, and change mothers' outlooks regarding the mode of delivery are essential [22]. Consequently, an instrument carefully assessing factors that affect the choice of delivery methods by mothers is required. Fear, attitude, perceived behavioral control, subjective norms, and behavioral intention are among the most common reasons to select a cesarean Sect. [23-25]. It has been confirmed that negative attitudes are the leading causes to select any particular means of delivery [23]. Other studies have also confirmed that doctors, midwives, and relatives' thoughts, as well as concepts such as attitude, perceived behavioral control, subjective norms, and behavioral intention, are the key constructs of the theory of reasoned action (TRA).

TRA comprises theoretical constructs such as attitude (beliefs about the behavior' outcome and evaluations of expected outcomes) and subjective norms (normative beliefs and motivation to comply) [26]. Thus, TRA can be a suitable theory to design interventional programs. As such, a valid and reliable questionnaire is required to extract personal intention. Various studies have been conducted about cesarean sections in Iran [9, 17, 21, 27, 28 ], but in these studies, researcher-made questionnaires were used, and there remains a lack of suitably validated instruments to measure women's intentions regarding their selection of delivery method.

Given the lack of a valid scale in Iran and other countries to measure factors predicting choice of delivery method and considering that the choice of delivery method is rooted in sociocultural background, the current study was aimed at the development and psychometric assessment of a questionnaire based on TRA to better understand Iranian pregnant women's intention toward cesarean section. Such scales could support the identification of the viewpoints of health experts and policymakers and, in turn, help in developing extended interventional plans for regulating the rate of the cesarean birth procedure. It is hoped this might aid in filling in the gaps and might contribute to the current literature on the topic.

\section{Methods}

\section{Participants and procedures}

This cross-sectional validation study was performed in the city of Sari, the capital of Mazandaran province, northern Iran, from February to June 2017. In the present study, the sample size was estimated based on the number of items in the scale, multiplying by 10 $(24 \times 10=240)$. The most commonly used minimum sample size estimation method in structural equation modeling (SEM) is the 10-times rule procedure, which makes on the hypothesis that the sample size should be higher than 10 times the maximum number of internal or external model links implying at any latent variable in the model. The 10-times rule was preferred due to its simplicity of use [29, 30]. In all, 480 pregnant women participated in exploratory factor analysis (EFA) (240 pregnant women) and confirmatory factor analysis (CFA) (240 pregnant women). Data for this study came from pregnant women who attended a Baghban specialist clinic, public health care centers, and private gynecological clinics in Sari. Women were chosen using a multistage random sampling method. The first step of the sampling method was aimed at selecting samples from all regions. To this end, a list of public health care 
centers and gynecological clinics was provided. Subsequently, in proportion to the number of target groups in each of the public and private service centers, the number of samples required was consecutively entered into the study via a simple sampling method.

The inclusion criteria were to be a pregnant woman with gestational age from the seventh to the ninth month and to be interested in participating in the study. Exclusion criteria were a lack of willingness, having a mental illness, or having a specific physical condition such as complete placenta Previa, which was an absolute indication for cesarean delivery with no option for a vaginal birth, making it impossible to participate and complete the questionnaire. The demographic characteristics of the women included age, level of education, and employment status. Data collection approaches were based on nameless scales that were completed by an expert interviewer for protecting the privacy of women and the confidentiality of the data. The interviewer received guidelines for similarly completing the scales after attending a training session.

\section{Scale development process}

This study was performed to develop an instrument to measure the intention of pregnant women to choose the cesarean section delivery method. The scale was developed across several stages. During the first stage, the content domain of the construct was specified. In this stage, interviews were conducted with the experts (gynecologists and midwives) and pregnant women, and a review of the literature relating to the TRA [31-35] was performed to develop an item pool and content domain. The main dependent variable in the present analysis was the cesarean delivery method. In addition, the independent variables included five factors, organized into a logical framework, as follows: (a) behavioral beliefs; (b) evaluation of behavioral outcomes; (c) motivation to comply; (d) normative beliefs; and (e) behavioral intention. The item pool contained 39 items at this point. The principal researcher and other team members then read the items and removed extraneous ones. The first draft of the instrument comprised 27 items. In the second stage, the psychometric properties of the Iranian version of the Theory-Based Intention to Cesarean Section (IR-TBICS) scale were examined to assess its validity and reliability.

\section{Content validity}

Content validation requires a wide-ranging review by a panel of experts to determine whether the scale items sufficiently address the subject they aim to assess. It is a crucial phase for developing a tool and a method for linking abstract notions with tangible and measurable indices. The expert panel comprised 10 specialists in health education and promotion, gynecologists, and experts familiar with scale making. Qualitative content validity was assessed in terms of the wording, scaling, grammar, and item allocation indices [36]. All items were tested, and the expert panel's suggestions were added to the scale. We applied the content validity index (CVI) and content validity ratio (CVR) to reach the quantitative content validity of the new scale. To measure CVR, the expert panel was questioned to evaluate each item through a 3-point Likert scale, where $1=$ essential, $2=$ useful but not essential, and $3=$ unessential. The CVR for each item was measured by means of the following formula: $\mathrm{CVR}=[\mathrm{Ne}-(\mathrm{N} / 2)] \div(\mathrm{N} / 2)(\mathrm{Ne}$ is the number of panelists indicating "essential" for each particular item and $\mathrm{N}$ is the total number of the professional panel). The numeric value of CVR is documented by the Lawshe table. Based on Lawshe's table [37], items with a CVR score of 0.62 or above were selected [36]. For the CVI, consistent with Waltz and Bausell [38], the same panel was questioned to assess the items based on a 4-point Likert scale on "relevancy," "clarity," and "simplicity." The number of those rating the item as relevant or clear (rating 3 or 4) was allocated by the number of a content expert panel. A CVI score of 0.79 or above was applied acceptable [37, 39].

\section{Face validity}

Face validity is a calculation of laywomen (pregnant women) in understanding and knowing an instrument. In this step, both quantitative and qualitative methods were used. For the quantitative step, ten pregnant women were questioned to assess the instrument and the degree of importance of each item on a 5-point Likert scale to evaluate the "Item Impact Score" (Impact Score $=$ Frequency $(\%) \times$ Importance $).$ An impact score equal to 1.5 or more was considered acceptable, as declared [40]. For the qualitative step, the same pregnant women were questioned about the 'relevancy,' 'ambiguity,' and 'difficulty' of each item, and some minor modifications were performed on the primary instrument.

\section{A preliminary version of the instrument}

Reflecting the above methods, a preliminary version of the instrument containing 24 items was created for the next phases (construct validity and reliability of the IR-TBICS scale).

\section{Statistical analysis Construct validity}

The construct validity of the IR-TBICS scale was assessed using both exploratory (EFA) and confirmatory factor analyses (CFA). 


\section{Main study and data collection}

A cross-sectional study was planned to assess the psychometric properties of the IR-TBICS scale. A consecutive sample of pregnant women was recruited from the Baghban specialist clinic, public health care centers, and private clinics of gynecologists affiliated with Mazandaran University of Medical Sciences.

a) Exploratory factor analysis (EFA) A sample of 240 pregnant women completed the IR-TBICS scale, and its factor structure was extracted by principal component analysis with varimax rotation. Bartlett's test of sphericity and the Kaiser-Meyer-Olkin (KMO) test were applied to assess the suitability of the sample for the factor analysis. Eigenvalues above one and scree plot were conducted to identify the number of factors. Factor loadings equal to or greater than 0.4 were considered appropriate [41].

b) Confirmatory factor analysis (CFA) A separate sample of 240 pregnant women completed the IR-TBICS scale, and factor analysis was conducted to measure the model fitness. As suggested, several fit indices counting relative chi-square $\left(\chi^{2} / \mathrm{df}\right)$, goodness of fit index, normed fit index, non-normal fit index, standardized root mean square residual, comparative fit index, and root mean square error of approximation were accompanied [42, 43]. Relative chi-square is the ratio of the chi-square to degrees of freedom, and its suggested reference value is less than three for accepting the fitness of the model. The values for GFI, CFI, NFI, and NNFI could range between 0 and 1; values closer to 1 reveal data fitness [44, 45]. An RMSEA ranging from 0.08 to 0.10 displays an average fit; less than 0.08 identifies a good fit [43]. The satisfactory value for SRMR is below 0.10 ; values under 0.08 display satisfactory fit, and values less than 0.05 show good fit [46].

\section{Reliability}

Cronbach's $\alpha$ coefficient assessed the internal consistency of the IR-TBICS scale. A Cronbach's $\alpha$ coefficient equal to 0.7 or more was identified as acceptable [47]. Floor and ceiling effects were determined as present if more than $15 \%$ of the responders attained the lowest or highest possible total score on the IR-TBICS scale [43]. Furthermore, a subsample of pregnant women $(n=25)$ completed the IR-TBICS scale twice with a 2-week interval to test the stability of the IR-TBICS scale by computing the intraclass correlation coefficient (ICC); an ICC of 0.4 or more was deemed acceptable [48]. All statistical analyses, except CFA, were done using SPSS v22.0 [49]. The CFA was done using the AMOS software v22.0 for Windows [50].

\section{Scoring}

In the final version of the IR-TBICS, a minimum of three and a maximum of seven items were generated for each construct. In the present study, behavioral beliefs and outcome evaluation toward cesarean section were measured with seven and five items, respectively. The items were rated on a 5-point scale ranging from 1 (strongly disagree) to 5 (strongly agree). Higher scores indicate a more positive attitude toward cesarean section. Normative beliefs were assessed concerning other important factors. In the present study, normative beliefs toward cesarean section were measured with six items. The items were rated on a 5-point scale ranging from 1 (strongly disagree) to 5 (strongly agree). In the present study, the motivation to comply with cesarean section was measured with three items. The items were rated on a 5 -point scale ranging from 1 (strongly disagree) to 5 (strongly agree). Higher scores indicate more subjective norms persuasive to cesarean section. The intention was assessed using three items. The items were rated on a 5point scale ranging from 1 (very unlikely) to 5 (very likely). Higher scores indicate more intention to have a cesarean section.

\section{Ethics}

The ethics committee of Mazandaran University of Medical Sciences approved the study. All pregnant participants gave their written informed consent.

\section{Results \\ Sociodemographic characteristics}

Overall, 480 pregnant women participated in the study. The age of respondents ranged from 14 to 41 years, with a mean age of 27.72 years $(S D=5.74)$. Regarding educational level, $11.87 \%$ of respondents attained the primary level, 33.33\% attained the secondary level, and 54.8\% attained the higher level of education. Of the total, $23.9 \%$ of the participants were housewives, and the majority of the women $(76.05 \%)$ were employed. The characteristics of the women are reported in Table 1.

\section{Feasibility}

The results showed no ceiling effect or floor effect for the Iranian version of the belief-based cesarean section scale.

\section{Content validity}

In the quantitative content validity assessment of the IRTBICS scale, items with a CVR and a CVI less than 0.62 and 0.80 , respectively, were removed. Three items were deleted, resulting in a 24-item pool. The expert panel also revised the IR-TBICS scale with regard to grammar, wording, and item allocation. The results of the quantitative content validity assessment indicated that the mean scores for the CVI and CVR were 0.87 and 0.83 , respectively. 
Table 1 Characteristics of the study sample

\begin{tabular}{lll}
\hline & $\begin{array}{l}\text { EFA sample } \\
(\boldsymbol{n}=\mathbf{2 4 0}) \\
\text { Number (\%) }\end{array}$ & $\begin{array}{l}\text { CFA sample } \\
(\boldsymbol{n}=\mathbf{2 4 0}) \\
\text { Number (\%) }\end{array}$ \\
\hline Age (years) & $12(5)$ & $10(4.2)$ \\
$<20$ & $132(55)$ & $136(56.7)$ \\
$20-29$ & $96(40)$ & $94(39.1)$ \\
$>29$ & $27.72(5.74)$ & $27.84(4.77)$ \\
Mean (SD) & $14-41$ & $14-41$ \\
Range & & $27(11.2)$ \\
Level of education & $30(12.5)$ & $76(31.7)$ \\
Primary & $84(35)$ & $137(57.1)$ \\
Secondary & $126(52.5)$ & \\
Higher & & $46(19.17)$ \\
Employment status & $69(28.8)$ & $194(80.83)$ \\
Housewife & $171(71.2)$ & \\
Employed & &
\end{tabular}

\section{Face validity}

In the qualitative face validity assessment, women stated small variations in the wording of some items for more description. The result of quantitative face validity indicated that the affect score was equal to or greater than 1.5 for all items of the IR-TBICS scale. None of the items were deleted, and the first draft of the IR-TBICS scale, containing 24 items, was developed for the next phase of psychometric evaluation. In other words, the participants showed that they experienced no trouble reading and understanding the 24 items.

\section{EFA}

The results of the EFA are presented in Table 2; Fig. 1. The KMO and Bartlett's test revealed that the data were suitable for factor analysis (KMO index $=0.830, \mathrm{X}^{2}=$ 2298.389, $P<0.001)$. Principal component analysis with varimax rotation recognized five factors with eigenvalues greater than 1 and factor loading equal to or more than 0.50 , accounting for $62.46 \%$ of the variance observed. The factor loadings were as follows: (a) Factor 1 (outcome evaluations) included 7 items (items 7-13); (b) Factor 2 (behavioral beliefs) included 6 items (items 16); (c) Factor 3 (injunctive normative beliefs) included 5 items (items 14-18); (d) Factor 4 (behavioral intention) included 3 items (items 22-24); and (e) Factor 5 (motivation to comply) included 3 items (items 19-21).

\section{CFA}

The findings of the CFA of the general model with 24 items in five subscales indicated that the model was accepted in its present form (the relative chisquare $\quad(\mathrm{x} 2 / \mathrm{df})=2.606<3, \quad P<0.001 ; \quad$ RMSEA $=$
$0.077>0.08, \quad(95 \% \quad \mathrm{CI}=0.062-0.078) ; \quad \mathrm{CFI}=0.931>0.9$; $\mathrm{IFI}=0.914>0.9 ; \quad$ TLI $=0.892>0.8 ; \quad$ GFI $=0.913>0.9$; AGFI $=0.905)$. Thus, the CFA displays the suitability of the model and the appropriate fit of its structural model for the study samples (Fig. 2).

\section{Reliability}

The reliability of the IR-TBICS scale was assessed using internal consistency. The Cronbach's $\alpha$ coefficient for the dimensions ranged from 0.609 to 0.843 . In addition, the ICC for the theory-based cesarean section beliefs instrument dimensions was assessed, which ranged from 0.71 to 0.84 (acceptable). This supports the stability of the IR-TBICS scale. Internal consistency of behavior comprised one item; therefore, internal consistency reliability was not assessed. Ceiling and floor effects should be less than $15 \%$ to comprise all criteria and show the variations during the time; in the current study, no ceiling or floor effects were detected in the total score or any dimensions of the IR-TBICS. The Cronbach's $\alpha$ and ICC of the theory-based cesarean section beliefs instrument dimensions are presented in Table 3.

\section{Discussion}

Generally, the theory of planned behavior (TBI) affords a valuable theoretical framework for dealing with the complications of human social behavior [51]. The evaluation of theoretical structures is one of the most problematic and essential sectors in the study of theory-based health education and promotion. The evaluation of TRA structures is best reached by two approaches: a direct technique in which, for instance, the typical attitude of people is assessed regarding certain behaviors, and an indirect (belief-based) technique in which the particular behavioral beliefs and their outcomes are assessed [51, 52]. Indirect assessment of the TRA constructs concentrated on the cognitive structures of TRA. TRA assumes that people can have many opinions about any particular behavior. TRA emphasizes two types of beliefs: behavioral and normative [51]. By knowing cognitive-behavioral beliefs, factors influencing the encouragement to do determined behaviors are recognized and impacted in the intervention research. In the current project, the TRA structures were assessed using a complicated procedure.

The content of the IR-TBICS scale items was first established based on interviews with the experts and pregnant women and a review of the literature to ensure that this instrument covered all theoretical concepts linked to the intention of cesarean section. The results of the analysis due to the KMO index show adequate sample size and satisfactory factor analysis. After EFA, a five-domain scale that was extracted accounted for $62.46 \%$ of the variance, and the maximum expressed variations were linked to the behavioral beliefs as a first 
Table 2 Exploratory factory analysis of the IR-TBICS scale $(n=240)$

\begin{tabular}{|c|c|c|c|c|c|}
\hline Item & Factor 1 & Factor2 & Factor3 & Factor4 & Factor5 \\
\hline $\begin{array}{l}\text { Q8. Delivering my child by the planned cesarean section will aid in creating a } \\
\text { healthy relationship between my spouse and me. }\end{array}$ & .775 & 0.113 & -0.067 & 0.028 & 0.053 \\
\hline Q9. Caesarean section is generally easier than vaginal birth method. & .716 & 0.102 & 0.001 & 0.133 & 0.002 \\
\hline $\begin{array}{l}\text { Q7. A child born by cesarean section is more intelligent than a child born } \\
\text { from vaginal birth. }\end{array}$ & .684 & 0.096 & 0.021 & 0.255 & 0.099 \\
\hline $\begin{array}{l}\text { Q13. Delivering my child by the vaginal birth method can change my bodily } \\
\text { form. }\end{array}$ & 679 & 0.070 & 0.215 & 0.159 & 0.250 \\
\hline $\begin{array}{l}\text { Q10. Caesarean section delivery does not have a negative effect on } \\
\text { postpartum sexual relationships. }\end{array}$ & .548 & 0.275 & 0.165 & -0.393 & 0.190 \\
\hline Q11. Delivering my child by the planned cesarean section is convenient for me. & .541 & 0.042 & 0.446 & -0.019 & -0.009 \\
\hline $\begin{array}{l}\text { Q12. A planned cesarean section provide relief so I can bond more with my } \\
\text { child. }\end{array}$ & .539 & 0.365 & -0.047 & 0.053 & -0.183 \\
\hline $\begin{array}{l}\text { Q3. In my opinion, a woman with problems like pelvic stenosis should have a } \\
\text { caesarean section. }\end{array}$ & -0.020 & .735 & 0.387 & -0.172 & 0.138 \\
\hline $\begin{array}{l}\text { Q1. In all situations, doing cesarean section is more appropriate than the } \\
\text { vaginal birth method. }\end{array}$ & 0.103 & .716 & 0.013 & 0.166 & 0.123 \\
\hline $\begin{array}{l}\text { Q5. Delivering my children by the planned cesarean section is a significant } \\
\text { experience for me. }\end{array}$ & 0.300 & .688 & -0.098 & 0.018 & 0.198 \\
\hline $\begin{array}{l}\text { Q6. I do not think we have had any serious complications after childbirth by } \\
\text { cesarean section. }\end{array}$ & 0.201 & .672 & 0.362 & -0.142 & 0.209 \\
\hline $\begin{array}{l}\text { Q2. In my opinion, the problems of vaginal birth method are greater than } \\
\text { cesarean section. }\end{array}$ & 0.223 & .630 & 0.529 & 0.094 & 0.057 \\
\hline $\begin{array}{l}\text { Q4. It is important to me that I deliver my children by the planned cesarean } \\
\text { section. }\end{array}$ & 0.301 & .559 & 0.489 & 0.014 & 0.012 \\
\hline $\begin{array}{l}\text { Q18. To my spouse, delivering my child at a specific time of day and at a } \\
\text { specific time of the year can impact my child's success in life. }\end{array}$ & -0.021 & 0.091 & .734 & -0.063 & 0.157 \\
\hline Q15. My spouse believes that the planned cesarean section is unsafe for me. & 0.138 & -0.015 & .656 & -0.184 & 0.234 \\
\hline $\begin{array}{l}\text { Q17. Delivering my child by the planned cesarean section is an important } \\
\text { experience for my spouse. }\end{array}$ & -0.119 & 0.196 & .556 & -0.024 & 0.351 \\
\hline Q14. My spouse believes that the planned cesarean section is risky for my child. & -0.015 & 0.346 & .534 & 0.044 & 0.226 \\
\hline $\begin{array}{l}\text { Q16. My family believe that the planned cesarean section is hazardous for my } \\
\text { child. }\end{array}$ & 0.448 & 0.393 & .529 & -0.008 & 0.028 \\
\hline $\begin{array}{l}\text { Q20. I believe that it is important to my family that I deliver my child by the } \\
\text { planned cesarean section. }\end{array}$ & 0.184 & 0.040 & -0.056 & .846 & -0.041 \\
\hline $\begin{array}{l}\text { Q19. I believe that it is important to my spouse that I deliver my child by the } \\
\text { planned cesarean section. }\end{array}$ & 0.261 & 0.082 & -0.027 & .814 & -0.029 \\
\hline $\begin{array}{l}\text { Q21. I believe that it is preference of doctor that I deliver my child by the } \\
\text { planned cesarean section. }\end{array}$ & 0.447 & 0.383 & 0.266 & .458 & 0.070 \\
\hline Q22. I intend to have my childbirth by cesarean section method. & 0.119 & 0.234 & 0.102 & -0.077 & .780 \\
\hline Q24. I plan to deliver my child using the planned cesarean section method. & -0.015 & 0.193 & 0.289 & -0.004 & .732 \\
\hline $\begin{array}{l}\text { Q23. I would like to deliver my child using the planned cesarean section } \\
\text { method. }\end{array}$ & 0.176 & 0.004 & 0.360 & -0.044 & .555 \\
\hline
\end{tabular}

Note. Figures in bold are related to factor loadings equal to or greater than 0.40

domain. Ghazanfari (2010) [53] also indicated that the theory of planned behavior (TPB) described $62 \%$ of the variance of physical activity, and attitude explained the maximum amount of variance. A CFA disclosed that the fit of the data was satisfactory. As such, the final IRTBICS scale contained 24 items, with seven items indicating outcome evaluations, six items representing behavioral beliefs, five items representing injunctive normative beliefs, three items representing behavioral intention, and three items representing motivation to comply with cesarean section.

Reliability is discussed with regard to the consistency and stability of the domains of a scale that represent its evaluation accuracy [54]. The findings of Cronbach's $\alpha$ 


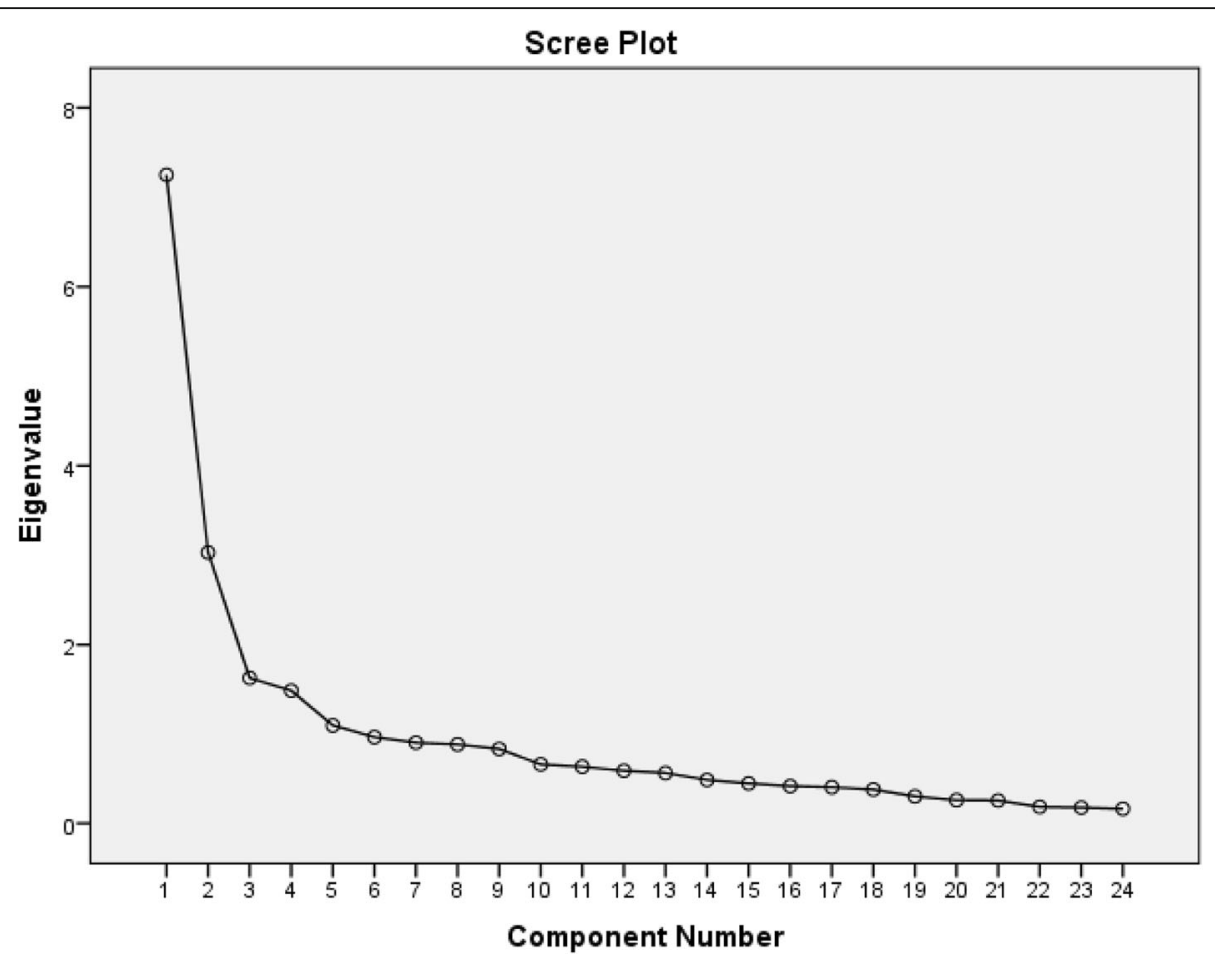

Fig. 1 Scree plot for determining factors of the designed instrument

coefficients between 0.609 and 0.843 for all domains indicated that the IR-TBICS scale had satisfactory reliability. Therefore, we believe the IR-TBICS scale represents a new scale for understanding the intention to choose the method of cesarean section delivery. Even though two domains (motivation to comply and behavioral intention) had a lower level of Cronbach's $\alpha$ (under 0.70 ), other domains had higher and acceptable levels of the Cronbach's $\alpha$ coefficient. However, no significant increase in the Cronbach's $\alpha$ coefficient was found after deleting any items. The results of the study performed by Bordewich in 2005 [55] indicated that the internal consistency of the TPB was between 0.52 and 0.89 . The internal consistency of the TPB domains was also reported to range from 0.54 to 0.82 [53]. In this study, there was no ceiling or floor effect in the total score for any dimensions of the IR-TBICS scale, which shows good content validity of the IR-TBICS scale in pregnant women. The low value of the Cronbach's $\alpha$ coefficient in some domains may be a result of the low number of items in the domains on how to develop the scale. It is essential that in the current study, the domains of motivation to comply and behavioral intention had three items, although Francis highlighted the existence of at least three items for each factor in the development guide of the TPB scale [52]. Moreover, Ajzen believed that matching items with prior research when developing the scale would result in an instrument with relatively low reliability, which may underestimate the correlation between domains of the theory [51]. It appears that adding the items for some factor can raise the scale reliability; therefore, considering this point, further research has been proposed.

Additionally, the ICC score revealed appropriate stability for the IR-TBICS scale, as it was measured by 25 pregnant women at a 2-week interval (0.79). As such, we believe that this newly developed scale may be particularly valuable for health care groups to know and plan procedures that are useful and targeted to specific conditions. The inclusion of five domains in the IR-TBICS scale further lets professionals identify domains in which a person can be improved.

Although the current study has several strengths, it also has some limitations. First, the present study was done among a sample of pregnant women from the city of Sari (northern Iran) to express their beliefs and intentions about the method of cesarean section delivery. Given this, we cannot be sure that our conclusions can be generalized to pregnant women from other geographic backgrounds. Consequently, further research may be needed to support the applicability of the beliefbased cesarean section delivery scale as a fully confirmed applied and useful measure for women of Iranian background. On the other hand, it would be better to investigate doctors' beliefs and intentions when choosing a delivery method for a woman. There is evidence 


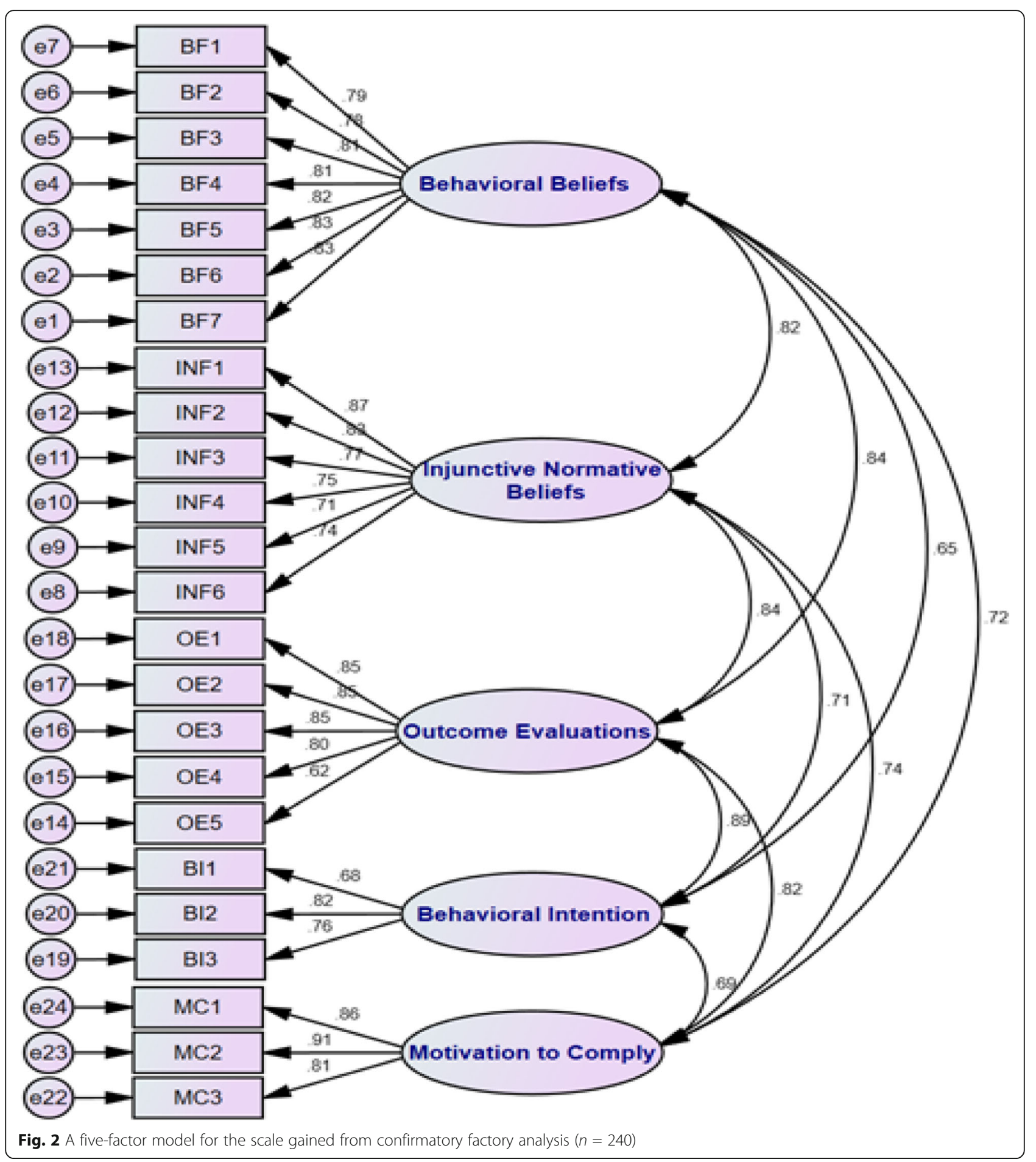

of doctors' fear of childbirth and preference for cesarean Sect. [56]. Second, the Cronbach's $\alpha$ coefficients of some factors were not satisfactory. Future studies are needed to overcome these problems.

In summary, one of the objectives of the century is to reduce unnecessary cesarean Sect. [57]. To do so, we developed the IR-TBICS scale, which was revealed to have acceptable psychometric properties. The IR-TBICS scale assesses the beliefs and intention of choosing cesarean section delivery that help to promote pregnant women's health.

\section{Conclusions}

Generally, the IR-TBICS scale indicated good construct validity, and the majority of domains indicated high 
Table 3 Measures of internal consistency and stability of the IR-TBICS scale

\begin{tabular}{lllll}
\hline Factor & The name of factor & Number of items & \multicolumn{1}{c}{$\begin{array}{l}\text { Cronbach alpha } \\
(\boldsymbol{n}=\mathbf{2 4 0})\end{array}$} & $\begin{array}{l}\text { ICC } \\
(\boldsymbol{n}=\mathbf{2 5})\end{array}$ \\
\hline $\mathbf{1}$ & Outcome evaluations & 7 items (7-13) & 0.74 & 0.81 \\
$\mathbf{2}$ & Behavioral beliefs & 6 items (1-6) & 0.80 & 0.79 \\
$\mathbf{3}$ & Injunctive normative beliefs & 5 items (14-18) & 0.84 \\
$\mathbf{4}$ & Behavioral intention & 3 items (22-24) & 0.61 & 0.84 \\
$\mathbf{5}$ & Motivation to comply & 3 items (19-21) & 0.64 & 0.71 \\
Total & & 24 items & 0.88 & 0.78 \\
\hline
\end{tabular}

internal consistency reliability; therefore, the results of the present study suggest that the theory-based cesarean section delivery beliefs scale is a valid and reliable questionnaire for measuring the beliefs of pregnant women. Furthermore, further studies are suggested to determine the strengths and weaknesses of the IR-TBICS scale when it is applied to other backgrounds.

\section{Appendix \\ Behavioral beliefs}

1. In all situations, doing a cesarean section is more appropriate than the vaginal birth method.

2. In my opinion, the problems of the vaginal birth method are more significant than a cesarean section.

3. In my opinion, a woman with problems like pelvic stenosis should have a cesarean section.

4. It is important to me that I deliver my children by the planned cesarean section.

5. Delivering my children by the planned cesarean section is a significant experience for me

6. I do not think we have had any severe complications after childbirth by cesarean section.

\section{Outcome evaluations}

7. A child born by a cesarean section is more intelligent than a child born from a vaginal birth.

8. Delivering my child by the planned cesarean section will aid in creating a healthy relationship between my spouse and me.

9. Cesarean section is generally more comfortable than a vaginal birth method.

10. Cesarean section delivery does not hurt postpartum sexual relationships.

11. Delivering my child by the planned cesarean section is convenient for me.

12. A planned cesarean section will provide relief so I can bond more with my child.

13. Delivering my child by the vaginal birth method can change my bodily form.

\section{Injunctive normative beliefs}

14. My spouse believes that the planned cesarean section is risky for my child.

15. My spouse believes that the planned cesarean section is unsafe for me.

16. My family believes that the planned cesarean section is hazardous for my child.

17. Delivering my child by the planned cesarean section is an essential experience for my spouse.

18. To my spouse, delivering my child at a specific time of day and at a specific time of the year can impact my child's success in life.

\section{Abbreviations \\ CFI: Comparative Fit Index; CVI: Content validity index; CFA: Confirmatory factor analysis; CVR: Content validity ratio; CDMR: Cesarean delivery on maternal request; EFA: Exploratory factor analysis; GFI: Goodness of Fit Index; ICC: Intraclass correlation coefficient; KMO: The Kaiser-Meyer-Olkin; \\ NFI: Normed Fit Index; NNFI: Non-Normed Fit Index; RMSEA: Root Mean Square Error of Approximation; SRMR: Standardized Root Mean Square Residual; TRA: Theory of Reasoned Action; TPB: Theory of Planned Behavior; IR-TBICS: Theory-based Intention to Cesarean Section; WHO: World Health Organization}

\section{Acknowledgements}

We would like to thank all the pregnant women for their participation in the current study as well as the experts without whose support the current research would not have been finalized. The authors are also grateful for the support received from the deputy of research, Mazandaran University of Medical Sciences (MAZUMS)

\section{Authors' contributions}

AN was the chief researcher, designed the study, and collected the data. MK participated in the statistics, the theory and design of the manuscript, and critically revised the final article. MM participated in the development of the project. All authors read and approved the final version of the manuscript.

Funding

No external funding sources were provided for the present study.

\section{Availability of data and materials}

The datasets produced and analyzed throughout the present study are not publicly accessible due to the need to protect the participants' anonymity but are accessible from the corresponding author on reasonable demand.

\section{Ethics approval and consent to participate}

The study method was approved by the Medical Ethics Committee of Mazandaran University of Medical Sciences [Ethic code: IR. MAZUMS.REC1397.1518]. The current study involved only pregnant women who gave their informed consent. Thus, verbal informed consent was obtained from all pregnant women before the start of the study, and all women completed informed written consent after being informed of the 
aims of the research. Additionally, verbal consent was obtained from the husbands and parents. The IR-TBICS was distributed with the pregnant women remaining anonymous; there was no private information that could relate the answers to any of the persons in the current study. To uphold the rights of the women, no records of consent by name were kept. Each completed scale was given to the study fellow on the same day of data gathering.

\section{Consent for publication}

N/A

\section{Competing interests}

The authors declare that they have no competing interests.

\section{Received: 31 July 2019 Accepted: 15 December 2020}

\section{Published online: 05 January 2021}

\section{References}

1. D'Souza R. Caesarean section on maternal request for non-medical reasons: putting the UK National Institute of Health and Clinical Excellence guidelines in perspective. Best Pract Res Clin Obstet Gynaecol. 2013;27(2): 165-77.

2. Lavender T, Hofmeyr GJ, Neilson JP, Kingdon C, Gyte GM. Caesarean section for non-medical reasons at term. Cochrane Database Syst Rev. 2012;2012(3): CD004660.

3. Zhang J, Troendle J, Reddy UM, Laughon SK, Branch DW, Burkman R, et al. Contemporary cesarean delivery practice in the United States. Am J Obstet Gynecol. 2010;203(4):326.e1-e10.

4. Betrán AP, Torloni MR, Zhang J-J, Gülmezoglu A, Section WWGoC, Aleem H, et al. WHO statement on caesarean section rates. BJOG. 2016;123(5):667-70,

5. TorkZahrani S. Commentary: childbirth education in Iran. J Perinat Educ. 2008;17(3):51-4

6. Bani S, Seied RA, Shamsi GT, Ghojazadeh M, Hasanpoor S. Delivery agents preferences regarding mode of delivery for themselves and pregnant women (Obstetrics, Gynecologists, Midwives); 2010.

7. Shareferad G, Fathean Z, Terane M, Mahake B. The survey of pregnant women views about delivery and cesarean according behavioral intention model. Ilam Univ Med Sci J. 2007:15:19-23.

8. Bettes BA, Coleman VH, Zinberg S, Spong CY, Portnoy B, DeVoto E, et al. Cesarean delivery on maternal request: obstetrician-gynecologists knowledge, perception, and practice patterns. Obstet Gynecol. 2007;109(1): 57-66.

9. Ahmad Nia S, Delavar B, Eini Zinab H, Kazemipour S, Mehryar A, Naghavi M. Caesarean section in the Islamic Republic of Iran: prevalence and some sociodemographic correlates. 2009.

10. Alimohamadian M, Shariat M, Mahmoodi M, Ramezanzadeh F. The influence of maternal request on the elective cesarean section rate in maternity hospitals in Tehran, Iran. Payesh (Health Monitor). 2003;2(2):137-42.

11. Mohammaditabar S, Rahnama P, Mohammadi K. Cesarean section on maternal request in Tehran 2010-2011: incidence and predisposing factors. J Mazandaran Univ Med Sci. 2014;24(114):74-82.

12. Løvåsmoen EML, Bjørgo MN, Lukasse M, Schei B, Henriksen L. Women's preference for caesarean section and the actual mode of deliverycomparing five sites in Norway. Sex Reprod Healthc. 2018;16:206-12.

13. Ryding EL, Lukasse M, Parys ASV, Wangel AM, Karro H, Kristjansdottir $H$, et al Fear of childbirth and risk of cesarean delivery: a cohort study in six European countries. Birth. 2015;42(1):48-55.

14. Arjmandi Rafsanjani B. Farzin Moghaddam S. Assessment of the level of the pregnant women's knowledge towards the advantages and disadvantages of normal vaginal delivery and cesarean section, Tehran (2005). Razi J Med Sci. 2007;14(55):13-22.

15. Sehhati Shafai F, Kazemi S. Comparing maternal outcomes in nulliparous women in labor in physiological and conventional labor: a randomized clinical trial. J Mazandaran Univ Med Sci. 2013;22(97):122-31.

16. Bahrie M, Latifnejad $\mathrm{R}$, Abdollahian $\mathrm{E}$, Esmaili $\mathrm{H}$. Effect of midwife's psycologiy \&amp; physical \&amp; Educational supportive in duration of labor stages and lobor pain force. Sabzevar Uni Medl Sci J. 2004;11(1):23-4.

17. Abbaspoor Z, Moghaddam-Banaem L, Ahmadi F, Kazemnejad A. Women's fear of childbirth and its impact on selection of birth method: a qualitative study. Payesh (Health Monitor). 2014a;13(5):575-87.
18. Bagheri A, Alavi NM, Abbaszadeh F. Iranian obstetricians' views about the factors that influence pregnant women's choice of delivery method: A qualitative study. Women Birth. 2013;26(1):e45-9.

19. Abbaspoor Z, Moghaddam-Banaem L, Ahmadi F, Kazemnejad A. Iranian mothers' selection of a birth method in the context of perceived norms: A content analysis study. Midwifery. 2014b;30(7):804-9.

20. Sanavi FS, Rakhshani F, Ansari-Moghaddam A, Edalatian M. Reasons for elective cesarean section amongst pregnant women; a qualitative study. J Reprod Infertility. 2012;13(4):237.

21. Yazdizadeh B, Nedjat S, Mohammad K, Rashidian A, Changizi N, Majdzadeh R. Cesarean section rate in Iran, multidimensional approaches for behavioral change of providers: a qualitative study. BMC Health Serv Res. 2011:11(1):159.

22. Mungrue K, Nixon C, David Y, Dookwah D, Durga S, Greene K, et al. Trinidadian women's knowledge, perceptions, and preferences regarding cesarean section: how do they make choices? Int J Women's Health. 2010;2:387.

23. Abdolkarimi M, Mahmoodi H, Rezaie Moradali M, Zareipour M, Alinejad M, Movahed E. Prediction of delivery type based on the theory of planned

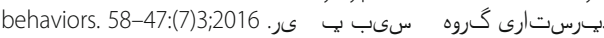

24. Mohammad BA, Tabatabaei S, Mohammad SN, Yazdani M. Factors influencing cesarean delivery method in Shiraz hospitals. 2009.

25. Hajian S, Shariati M, Najmabadi KM, Yunesian M, Ajami ME. Psychological predictors of intention to deliver vaginally through the extended paralle process model: a mixed-method approach in pregnant Iranian women. Oman Med J. 2013;28(6):395.

26. Ajzen I. The theory of planned behavior. Organ Behav Hum Decis Process. 1991:50(2):179-211.

27. Shahshahan Z, Heshmati B, Akbari M, Sabet F. Caesarean section in Iran. The Lancet. 2016:388(10039):29-30.

28. ShahrakiSanavi F, Navidian A, Rakhshani F, Ansari-Moghaddam A. The effect of education on base the Theory of Planned Behavior toward normal delivery in pregnant women with intention elective cesarean. Hormozgan Med J. 2014:17(6):531-9.

29. Peng DX, Lai F. Using partial least squares in operations management research: a practical guideline and summary of past research. J Oper Manag. 2012;30(6):467-80.

30. Hair JF, Ringle CM, Sarstedt M. PLS-SEM: indeed a silver bullet. J Market Theory Pract. 2011;19(2):139-52.

31. Salehi A, Ahmad-Shirvani M, Mousavinasab N, Aarabi M, Shahhosseini Z. Health-care providers' knowledge about prenatal screening: a study in the North of Iran. Nurs Midwifery Stud. 2019;8(2):112-7.

32. Moeini B, Hazavehei SMM, Bashirian S, Soltanian A, Mousali AA, Kafami V. Effect of educational program to encourage safe sexual behaviors among addicted men refered to substance abuse treatment centers in Hamadan, Western Iran: applying the theory of planned behavior. J Educ Community Health. 2014;1(1):1-10.

33. Barati M, Allahverdipour H, Moinei B, Farhadinasab A, Mahjub H. Evaluation of theory of planned behavior-based education in prevention of MDMA (ecstasy) use among university students. 2011

34. Bashirian S, Barati M, Fathi Y. Prevalence and factors associated with tramadol abuse among college students in west of Iran: an application of the theory of planned behavior. Avicenna J Neuro Psycho Physiol. 2014;1(1):26-30.

35. Jalilian F, Allahverdipour H, Moeini B, Moghimbeigi A. Effectiveness of anabolic steroid preventative intervention among gym users: Applying theory of planned behavior. Health promotion perspectives. 2011;1(1):32

36. Waltz CF, Bausell BR. Nursing research: design statistics and computer analysis. Davis FA; 1981.

37. Lawshe $\mathrm{CH}$. A quantitative approach to content validity 1. Pers Psychol. 1975:28(4):563-75.

38. Waltz CF, Strickland OL, Lenz ER. Measurement in nursing and health research. Berlin: Springer Publishing Company; 2010.

39. Polit DF, Beck $\subset$ T. Nursing research: principles and methods. Philadelphia: Lippincott Williams \& Wilkins; 2004

40. Lacasse Y, Godbout C, Series F. Health-related quality of life in obstructive sleep apnoea. Eur Respir J. 2002;19(3):499-503.

41. Norris M, Lecavalier L. Evaluating the use of exploratory factor analysis in developmental disability psychological research. J Autism Dev Disord. 2010; 40(1):8-20.

42. Kline RB. Software review: Software programs for structural equation modeling: Amos, EQS, and LISREL. J Psychoeduc Assess. 1998;16(4):343-64 
43. Terwee CB, Bot SD, de Boer MR, van der Windt DA, Knol DL, Dekker J, et al. Quality criteria were proposed for measurement properties of health status questionnaires. J Clin Epidemiol. 2007;60(1):34-42.

44. Harrington D. Confirmatory factor analysis. Oxford: Oxford University Press; 2009

45. Whittaker TA. A beginner's quide to structural equation modeling. Abingdon-on-Thames: Taylor \& Francis; 2011.

46. Fan Y, Chen J, Shirkey G, John R, Wu SR, Park H, et al. Applications of structural equation modeling (SEM) in ecological studies: an updated review. Ecol Processes. 2016;5(1):19.

47. Cronbach $\sqcup$. Coefficient alpha and the internal structure of tests. Psychometrika. 1951;16(3):297-334.

48. Munro BH. Statistical methods for health care research. Philadelphia: Lippincott Williams \& Wilkins; 2005.

49. Corp I. IBM SPSS statistics for windows, version 22.0. Armonk. NY: IBM Corp; 2013.

50. Spss I. IBM SPSS statistics 22. New York: IBM Corp; 2013.

51. Ajzen I. Constructing a TPB questionnaire: conceptual and methodological considerations. 2002.

52. Francis J, Eccles MP, Johnston M, Walker A, Grimshaw JM, Foy R, et al. Constructing questionnaires based on the theory of planned behaviour: a manual for health services researchers. Newcastle upon Tyne: Centre for Health Services Research, University of Newcastle upon Tyne; 2004.

53. Ghazanfari Z, Niknami S, Ghofranipour F, Hajizadeh E, Montazeri A. Development and psychometric properties of a belief-based Physical Activity Questionnaire for Diabetic Patients (PAQ-DP). BMC Med Res Methodol. 2010;10(1):104

54. Hajizadeh E, Asghari M. Statistical methods and analyses in health and biosciences a research methodological approach. Tehran: Jahade Daneshgahi Publications; 2011. p. 395.

55. De Bourdeaudhuij I, Klepp K-I, Due P, Rodrigo CP, De Almeida M, Wind $\mathrm{M}$, et al. Reliability and validity of a questionnaire to measure personal, social and environmental correlates of fruit and vegetable intake in 1011 -year-old children in five European countries. Public Health Nutr. 2005;8(2):189-200

56. Størksen HT, Garthus-Niegel S, Adams SS, Vangen S, Eberhard-Gran M. Fear of childbirth and elective caesarean section: a population-based study. BMC Pregnancy Childbirth. 2015;15(1):221.

57. Organization WH. WHO recommendations non-clinical interventions to reduce unnecessary caesarean sections. Geneva: World Health Organization; 2018.

\section{Publisher's Note}

Springer Nature remains neutral with regard to jurisdictional claims in published maps and institutional affiliations.

Ready to submit your research? Choose BMC and benefit from:

- fast, convenient online submission

- thorough peer review by experienced researchers in your field

- rapid publication on acceptance

- support for research data, including large and complex data types

- gold Open Access which fosters wider collaboration and increased citations

- maximum visibility for your research: over $100 \mathrm{M}$ website views per year

At $\mathrm{BMC}$, research is always in progress.

Learn more biomedcentral.com/submissions 